\title{
Authentication of Tunisian virgin olive oils by chemometric analysis of fatty acid compositions and NIR spectra. Comparison with Maghrebian and French virgin olive oils
}

\author{
S. Laroussi-Mezghani ${ }^{\mathrm{a}, \mathrm{b}, \mathrm{c}, *}$, P. Vanloot ${ }^{\mathrm{a}}$, J. Molinet ${ }^{\mathrm{a}}$, N. Dupuy ${ }^{\mathrm{a}}$, M. Hammami ${ }^{\mathrm{b}}$, N. Grati-Kamoun ${ }^{\mathrm{c}}$ \\ J. Artaud ${ }^{\mathrm{a}}$ \\ ${ }^{a}$ Aix-Marseille Université, LISA, EA4672, Équipe METICA, 13397 Marseille cedex 20, France \\ ${ }^{\mathrm{b}}$ Biochemistry Laboratory, LR12ES05 'Nutrition-Functional Food E' Vascular Health', USCR Mass Spectrometry, Faculty of Medicine, University of Monastir, Tunisia \\ 'Institut de l'Olivier, Unité Technologie et Qualité, BP 1087, 3018 Sfax, Tunisia
}

Keywords:

Fatty acids

NIR

Chemometrics

Authentication

Tunisian olive oils

\begin{abstract}
A B S T R A C T
Six Tunisian virgin olive oil (VOO) varieties, Chemlali Sfax, Chetoui, Chemchali, Oueslati, Zarrazi and Zalmati, were characterised by two analytical methods. The gas chromatography allowed the determination of 14 fatty acids and squalene amounts. With fatty acids of each variety, a characteristic "morphotypes" for each oil variety was established. Chemlali Sfax and Zalmati showed strong similarities. Gas chromatography of fatty acid methyl esters (FAME) and near infrared (NIR) spectra of oils, associated to chemometric treatment, allowed the study of the inter-varietal variability and the verification of the variety origins of some Tunisian commercial VOOs. The specificity of Tunisian VOOs was evaluated by comparing the samples to Algerian, Moroccan and French Protected Designation of Origin VOOs. Classification in varietal origins by SIMCA used the FAME compositions and NIR spectra of the most represented varieties (Chemlali Sfax, Chetoui and Oueslati) showed a high potential to authenticate the varietal origin of Tunisian VOOs.
\end{abstract}

\section{Introduction}

The olive oil sector plays a very important role in the economy of Tunisia and constitutes one of the main factors of economic and social stability in the country. In Tunisia, the olive trees spread almost over the whole of the territory. According to recent estimates, there are 78 million olive trees in Tunisian covering an area of 1.77 million hectares (Ministère de l'Agriculture, DGPA). This puts Tunisia second after Spain with nearly $19 \%$ of the worldwide olive-growing area.

Olive oil production in Tunisia represents $10 \%$ of the total agricultural production of the country. Tunisia produces 180.000 tons of olive oil making it the fourth world producer (6\%) of olive oil after Spain, Italy and Greece. Tunisia is also the fourth world exporter $(8.2 \%)$ of olive oil after Spain, Italy and Greece with almost 110.000 tons of olive oil exported every year.

\footnotetext{
* Corresponding author at: Aix-Marseille Université, Avenue Escadrille Normandie-Niémen, LISA, Équipe METICA, EA 4672, Case 451, 13397 Marseille cedex 20, France. Tel.: +216 23361449.

E-mail address: sonda.laroussi@yahoo.fr (S. Laroussi-Mezghani).
}

Tunisian orchards are rich in many varieties which have been the subject of a catalogue listing fifty-six different varieties (Trigui, Msallem, \& collaborateurs, 2002). A study by GratiKamoun and Khlif (2001), found more than seventy olive tree varieties in the country.

Nevertheless, the Tunisian olive grove is dominated by the two major varieties Chetoui in the North and Chemlali in the Centre and the South. However, based on biochemical and molecular markers, the denomination Chemlali has often been used, in the country, to refer to completely distinct varieties (Grati-Kamoun et al., 2006). So, in order to distinguish between the different varieties of Chemlali, the name of the production area was added to the name of the variety as in Chemlali Sfax or Chemlali Jerba (Grati-Kamoun \& Khlif, 2001).

Another important fact about Tunisian olive oil is that it is mostly produced without any pesticides and can be easily certified as organic production.

Despite the importance of the Tunisian olive oil heritage, most Tunisian olive oil is not highly valued on the national or the international markets. In fact, the majority of the Tunisian olive oil, about $90 \%$, is exported in bulk and assembled with other foreign oils that do not emphasise its characteristics. 
However, recently in Tunisia, there have been efforts to improve the reputation of the Tunisian olive oil on the international market. Such efforts not only aim to enhance the quality of the olive oil product in general, but also of specific varieties of olive oil by creating new quality signs such as Indication of Protected Origin (IPO) and Registered Designation of Origin (RDO).

In 2008, a study by the Agency for the Promotion of Agricultural Investments (APIA, 2008) has identified 21 areas eligible for the labels (IPO/RDO). This selection is based on variety, soil, climate and the know-how, but it does not take into account the physico-chemical characteristics of the oils. Many physico-chemical characteristics (acidity, peroxide value, $K_{232}, K_{270}$, compositions in phenolic components, volatile components, carotenoids, chlorophylls...) are highly dependent on the quality of the olives before harvest, the extraction process of oils and their conservation. Therefore, it is difficult to use them to characterise the geographical or varietal origins of oils on account of their changes during storage of oils. However, the characterisation of olive oil varieties and RDO olive oils by their fatty acid compositions give better results (Ollivier, Artaud, Pinatel, Durbec, \& Guérère, 2003). This characterisation supposes the determination of all the isomers of fatty acids with 16,18 and 20 carbon atoms but also the long-chain fatty acids with 22 and 24 carbon atoms. Numerous studies on the fatty acid composition of Tunisian olive oils from indigenous and other introduced varieties have been published, but many do not take into account all the fatty acids with amount greater than $0.01 \%$ even though they are involved in the characterisation of oils (Grati-Kamoun \& Zarrouk, 2012; Issaoui et al., 2007).

Furthermore, the authentication of olive oils can be achieved by an alternative and fast method based on the near-infrared spectra associated with a chemometric treatment (Bevilacqua, Bucci, Magrì, Magrì, \& Marini, 2012; Galtier et al., 2007; Woodcock, Downey, \& O’Donnell, 2008).

The aim of this work is (i) to characterise six Tunisian olive oils (Chemchali, Chemlali Sfax, Chetoui, Oueslati, Zalmati and Zarrazi) by their fatty acid compositions and near infrared spectra associated with chemometric treatment, (ii) to reveal their specificity compared to other Maghrebian (Algeria and Morocco) and French Protected Designation of Origin (PDO) oils and (iii) to predict the varietal origin of Tunisian olive oils using fatty acid compositions and NIR data.

\section{Materials and methods}

\subsection{Virgin olive oil samples}

Sampling was carried out during two successive crops (2010/ 2011 and 2011/2012). 247 Virgin olive oil (VOO) samples were used for this study. Tunisian VOOs $(n=133)$ were obtained in laboratory by oleodoseur extraction system, from handpicked olives of Chemchali $(n=5)(\mathrm{Ch})$, Chemlali Sfax $(n=63)(\mathrm{Cm})$, Chetoui $(n=41)(\mathrm{Ct})$, Oueslati $(n=14)(\mathrm{Ou})$, Zalmati $(n=5)(\mathrm{Zl})$ and Zarrazi $(n=5)(\mathrm{Zr})$ varieties.

Other Tunisian VOOs $(n=51)$ were the commercial ones (Chemchali $(n=2)$, Chemlali Sfax $(n=35)$, Chetoui $(n=12)$, Oueslati $(n=1)$, and Zarrazi $(n=1))$. Foreign VOO samples were used to verify the specificity of Tunisian ones: six mono-varieties from Algeria ( $n=22$ ) (A) (Azeradj, $n=4$; Blanquette, $n=7$; Bouricha, $n=2$; Chemlal, $n=5$; Limli, $n=3$; and Sigoise, $n=1$ ), one mono-variety from Morocco (M) $(n=5)$ (Moroccan Picholine) and French PDOs $(n=36)$. The PDOs are principally made up of primary and secondary varieties and also local and old varieties: "Haute-Provence" $(n=6)$, "Nice" $(n=6)$, "Nîmes" $(n=6)$ and "Nyons" $(n=6)$ are made up of one unique principal variety. "Aix-en-Provence" $(n=6)$ and
"Vallée des Baux de Provence" ( $n=6$ ) have up to three or four main varieties.

\subsection{Maturity index}

The maturity index (MI) of olives was established by visual appreciation of the colour samples of 100 fruits according to a colour scale varying from green-intense to a black skin and an entirely violet pulp. The maturity index values range from 0 to 7 (Uceda \& Frias, 1975).

\subsection{Quality criteria}

Free acidity (A), conventionally expressed in oleic acid ( $\mathrm{g} /$ $100 \mathrm{~g})$, peroxide value (PV) $\left(\mathrm{meqO}_{2} / \mathrm{kg}\right)$ and UV absorption characteristics $\left(\mathrm{K}_{232}\right.$ and $\left.\mathrm{K}_{270}\right)$ were determined according to International Olive Oil Council (IOOC (International Olive Oil Council), 2008).

\subsection{Pigment content}

The content of chlorophyll pigments $(\mathrm{mg} / \mathrm{kg})$ in the olive oil was determined using a Shimadzu UV-101PC spectrophotometer through the absorbance $(A)$ of VOO at 630,670 and $710 \mathrm{~nm}$. Samples were filled directly into a $1 \mathrm{~cm}$ path length glass cell $(L)$. Pure carbon tetrachloride was used as a reference (Wolff, 1968). The chlorophyll pigment was calculated by:

Chlorophyll $(\mathrm{mg} / \mathrm{kg})=\left[A_{670}-\left(A_{630}+A_{710}\right) / 2\right] /(0.1086 \times L)$

The carotene fraction was evaluated using a Shimadzu UV-101PC spectrophotometer by the absorbance measurement at $470 \mathrm{~nm}$ of a $7.5 \mathrm{~g}$ of oil sample dissolved in $25 \mathrm{ml}$ of cyclohexane and filled into a $1 \mathrm{~cm}$ path length glass cell. Cyclohexane was used as a reference. Results were expressed as $\mathrm{mg}$ of lutein, major carotenoids pigment, per $\mathrm{kg}$ of oil. The maximum at $470 \mathrm{~nm}$ was chosen being a zone without interference from pheophytin "a" after obtaining the corresponding coefficient of extinction. The values are calculated from that what given in the bibliography for lutein in ethanol (Minguez-Mosquera, Rejano-Navarro, GandulRojas, Sanchez-Gomez, \& Garrido-Fernandez, 1991).

\subsection{Fatty acid and squalene determinations}

Olive oil in 2,2,4-trimethylpentane (isooctane) $(\approx 0.12 \mathrm{~g} / 2 \mathrm{~mL})$ was trans-methylated with a cold solution of $\mathrm{KOH}(2 \mathrm{M})(200 \mu \mathrm{l})$ according to the European Standard NF EN ISO 5509 Norm (2000). Fatty acid methyl esters (FAME) were analysed according to the European Standard NF EN ISO 5508 Norm (1995). Analyses were performed on an Agilent Technology gas chromatograph 7890A (GC) equipped with a split/split-less injector $\left(T=250^{\circ} \mathrm{C}\right)$ and flame ionisation detector (FID) $\left(T=250^{\circ} \mathrm{C}\right)$. A silica capillary column $(60 \mathrm{~m} \times 0.25 \mathrm{~mm}$ i.d., $0.25 \mu \mathrm{m}$ film thickness) coated with polyethylene glycol (Supelcowax, Supelco, France) was used. The carrier gas was hydrogen (column flow $1 \mathrm{ml} / \mathrm{min}$ ) and the spilt ratio was 1:60. The oven temperature program was as follows: $20 \mathrm{~min}$ at $210^{\circ} \mathrm{C}$, from 210 to $245^{\circ} \mathrm{C}$ at $6^{\circ} \mathrm{C} / \mathrm{min}, 20 \mathrm{~min}$ at $245^{\circ} \mathrm{C}$. Fatty acid identification was realised in previous work by Ollivier et al. (2003). Fatty acid percentages were determined by internal standardization without taking into account mass response factors. Squalene percentage was determined through an internal standardization considering the sum of fatty acids and squalene as: 
Squalene $\%=$ Area Squalene $* 100 / \sum$ Area (fatty acids + squalene)

The repeatability of FAME was evaluated by esterifying 12 times the same VOO sample. The repeatability of the injection was also evaluated by injecting 12 times the same FAME sample. The coefficients of variation were lower than $5 \%$ for the most important fatty acids and lower than $10 \%$ for some other minor's ones.

\subsection{Mean indexes}

Four indexes characterising the VOO fatty acid were calculated. They are defined below:

- Mono-unsaturation index (MUI) is the ratio of the sum of mono-unsaturated fatty acids to the sum of saturated fatty acids.

- The poly-unsaturation index (PUI) is the ratio of poly-unsaturated fatty acids on the sum of saturated fatty acids.

- The total unsaturation index (TUI) is the ratio of mono-unsaturated fatty acids and poly-unsaturated on the sum of saturated fatty acids.

- Odd parity index (OPI) is the ratio of the sum of the odd fatty acids (17 carbon atoms: $17: 0$ to $17: 1 \omega 8$ ) to the sum of pair acids, multiplied by 1000 .

\subsection{Near-infrared spectroscopy (NIR)}

NIR spectra of each virgin olive oil were recorded with a Nicolet Antaris II spectrometer interfaced to a personal computer using the software result integration Thermo Nicolet 2.1. VOO samples were filled into a $2 \mathrm{~mm}$ path length quartz cell directly sampled from the bottle without any chemical treatment. Spectra were recorded between 4500 and $10000 \mathrm{~cm}^{-1}$ at $4 \mathrm{~cm}^{-1}$ resolution by co-adding 10 scans using double sided interferograms and an empty cell as a reference. The analyses were performed at $21^{\circ} \mathrm{C}$. The recorded spectra have been transformed by Standard Normal Variate (SNV) and Savitzky-Golay first derivative by the Unscrambler ${ }^{\circledR}$ (version 9.8., CAMO, Norway) software before chemometric treatments. Each spectrum is constituted of 2853 points.

\subsection{Unsupervised pattern recognition}

Principal component analysis (PCA) is an unsupervised pattern recognition and it is often the first step of exploratory data analysis to detect groups in the measured data (Jolliffe, 2002). PCA models the directions of maximum variations in a data set by projecting as a swarm of points in a space defined by principal components (PCs). PCs describe, in decreasing order, the higher variations amongst the objects, and because they are calculated to be orthogonal to another one, each PC can be interpreted independently. That permits an overview of the data structure by revealing relationships between the objects as well as the detection of deviating objects. To find these sources of variations, the original data matrix is decomposed into the object space, the variable space, and the error matrix. The error matrix represents the variations not explained by the previously extracted PCs and is dependent on the problem definition. The PCA algorithm of fatty acids was calculated with normalised data. Ten PCs were required to build models.

\subsection{Soft independent modelling of class analogy classification (SIMCA)}

SIMCA is the most used pattern recognition method for supervised classification data. (Wold \& Sjöström, 1977). The SIMCA classification is a method based on disjoint PCA modelling realised for each class in the calibration set. Unknown samples are then compared to the class models and assigned to classes according to their analogy with the calibration samples. A new sample will be recognised as a member of a class if it is enough similar to the other members; else it will be rejected. A model distance limit Smax is used for classifying new samples and Smax is calculated for the class model $\mathrm{m}$ as follows (Eq. (3)):

$\operatorname{Smax}(m)=S_{0}(m) \sqrt{ } \mathrm{FC}$

where $S_{0}$ is the average distance within the model, and Fc (Fisher criterion) is the critical value provided by the Fisher-Snedecor tables. The Fc value depends on the percentage of risks, generally set to 5\% (Galtier et al., 2011). Class membership is defined at a significance level of $2.5 \%$ of Smax. Mean centering is applied before modelling. The sum of samples (laboratory and commercial) used as training set in disjoint PCA is $n=111$ (Chemlali Sfax $n=65$, Chetoui $n=36$, and Oueslati $n=10)$. The prediction set $(n=134)$ was formed by the three Tunisian varieties (laboratory and commercial) $(n=55)$ Chemlali Sfax $(n=33)$, Chetoui $(n=17)$ and Oueslati $(n=5)$ and Other ones $(n=79)$, amongst them Chemchali $(n=5)$, Zalmati $(n=5)$ and Zarrazi $(n=6)$ and foreign oils from France (PDOs; $n=36$ ), Algeria ( $n=22$ ) (Azeradj, Blanquette, Bouricha, Chemlal, Limli, and Sigoise) and Morocco $(n=5)$.

The percentage of correct classification (\%CC) is the criterion used to compare classification results obtained with chemometric methods:

$\% \mathrm{CC}=\mathrm{Nc} \cdot 100 /(\mathrm{Nc}+\mathrm{Nic})$

where $\mathrm{Nc}$ is the number of correct classifications and Nic is the number of incorrect classifications.

\subsection{Software}

The chemometric applications are performed by the Unscrambler software version 9.8 from CAMO, Norway.

\subsection{1. "Morphogram", "Morphotype"}

A graphical radial plot ("morphogram") characterising the variety origin, made with Excel ${ }^{\circledR} 2003$ spreadsheet (Microsoft Corporation), was realised. This representation was based on the difference between fatty acids data compared to the average of the same variables obtained from a database built with more than 2900 samples from various sources, grouped by variety and origin (Pinatel, Ollivier, Ollivier, \& Artaud, 2014).

The "morphotypes" are developed from the "morphograms". They are a graphical representation of the fatty acid composition of a minimum five oil samples $(n \geqslant 5)$ of the same variety. Each axis on the "morphogram" illustrated the change for a given variable with the respect of the mean centred value, which gives the origin of the graphics $(0 \%)$. The limits of variation $(-100 \%$ to $+100 \%)$ is equal to twice the standard deviation of the variable for fatty acids. The solid line is the median values of individual fatty acids and the dotted lines to first and third quartiles. Thus, on each axis, the value gives the change percentage compared to two times the standard deviation (Ollivier, Pinatel, Dupuy, Guérère, \& Artaud, 2007).

\subsection{Nomenclature}

Fatty acids: 14:0, myristic acid (tetradecanoic acid); 16:0, palmitic acid (hexadecanoic acid); 16:1 $\omega 9$, hypogeic acid, (7-hexadecenoic acid); 16:1 $\omega 7$, palmitoleic acid (9-hexadecenoic acid); 17:0, margaric acid (heptadecanoic acid); 17:1 $\omega 8$, margaroleic acid, (9-heptadecenoic acid); 18:1 $\omega 9$, oleic acid (9-octadecenoic acid);

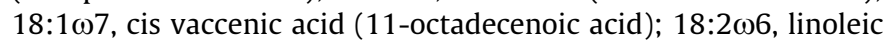

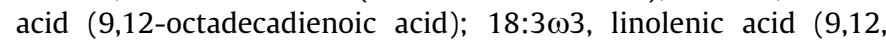


15-octadecatrienoic acid); 20:0, arachidic acid (eicosanoic acid); 20:1 $\omega 9$, gondoic acid (11-eicosenoic acid); 22:0, behenic acid (docosanoic acid); 24:0, lignoceric acid (tetracosanoic acid).

\section{Results and discussion}

The quality criteria (acidity, peroxide values and UV specific extinction) was determined for all olive oil samples produced in laboratory scale $(n=133)$. The values of these parameters (Table 1 ) were included in the ranges established for Extra virgin olive oil (EVOO) category (IOOC (International Olive Oil Council)., 2008). This result was expected knowing that the oils were obtained from handpicked fresh olives and without storage time before the extraction. The quality criteria depend essentially on the olive quality before the extraction and the storage oil conditions. Some authors (Baccouri et al., 2007) reported that the free acidity increased from $0.1 \%$ to $0.15 \%$ at a maturity index about 1 and from $0.2 \%$ to $0.3 \%$ at a maturity index close to 5 while peroxide value and $\mathrm{K}_{232}$ and $\mathrm{K}_{270}$ extinction coefficients decrease slightly during ripening. In order to limit the effect of ripening stage on the studied physico-chemical parameters, sampling was realised during December 2011. Maturity indexes were around 3 for Chemchali, Chemlali Sfax, Zalmati and Zarrazi varieties. Chetoui and Oueslati cultivated in cold and mountainous regions in the north and the centre of Tunisia, showed lower values around 2 .

In addition to their antioxidant activities, the pigments are responsible for the oil colour, which is one of the factors that influence selection by consumers (Baccouri et al., 2007). The stage of maturity is very important for pigment concentration in VOOs. The content of chlorophyll pigments and carotenoids decreased markedly during the maturity to only a few $\mathrm{mg} / \mathrm{kg}$ (Ouni, Flamini, Douja, \& Zarrouk, 2011). For the studied oils, chlorophylls were found at average concentrations between 1.23 and $5.97 \mathrm{ppm}$ whereas the average concentration of carotenes varied between 3.28 and $8.88 \mathrm{ppm}$ according to varieties (Table 1). Chemlali Sfax and Zarrazi present higher amounts in chlorophylls and carotenoids than Chemchali and Zalmati (approximately the same stage of the maturity). Chetoui have higher concentrations in pigments than Oueslati variety. The highest amounts of chlorophylls and carotenes were observed in the oils of Chetoui and Oueslati varieties. This result was also observed by Ouni et al. (2011) when they studied the effect of variety on minor components of Chemlali Sfax, Chetoui and Oueslati varieties.

\subsection{Fatty acids}

The fatty acid composition of 133 Tunisian VOO samples was determined by gas chromatography of their fatty acid methyl esters. For all the samples, 14 fatty acids and squalene were identified and quantified. Table 1 shows for each variety, the mean, minimum and maximum of each fatty acid with a rate greater than $0.01 \%$ and the four indexes (MUI, PUI, TUI and OPI) defined above.

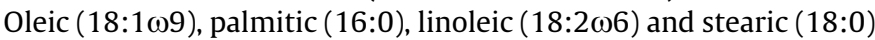
are the major fatty acids commonly found in HOVs. Isomers of monounsaturated fatty acid with sixteen (hypogeic acid, 16:1 19

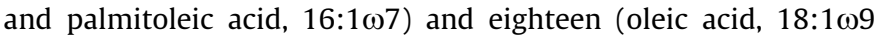
and cis-vaccenic acid, 18:1 $\omega 7$ ) carbon atoms, are determined separately. The identification method used in this study is more thorough and brings more information than the European regulation one that regroups isomers together (Ollivier et al., 2003). This approach was already used for the characterisation of French VOO fatty acids, but never for Tunisian ones. The differentiation of the structural (position) isomers of fatty acids in C16 and C18 brings a better knowledge of the chemical composition of olive oil and can be of great interest in studying their nutritional impact.

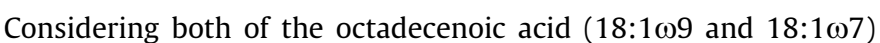

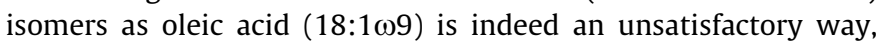
from both chemical and nutritional points of view. Six minor fatty acids were also determined: 17:0, 17:1 $\omega 8,20: 0,20: 1 \omega 9,22: 0$, and $24: 0$. Eicosenoic acid $(20: 1)$ is attributed very often in the literature

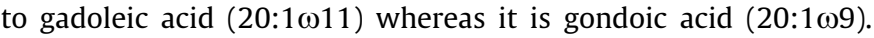
These acids although minor are important for characterisation of varieties (Ollivier et al., 2003).

Fatty acid composition varies markedly with variety and stage of maturity. At the beginning of fruit development, palmitic acid content was high, followed by an extreme decrease, then it remained unchanged until the end of fruit development (Baccouri et al., 2007). One sample of Chemlali Sfax oil showed, at low maturity index $(\mathrm{MI}=1)$, palmitic and oleic acid fractions out of the limit fixed by the IOOC. This result can be observed when summer and autumn are very hot. In very specific conditions (very low maturity index $<2$ and excessive heat $>41^{\circ} \mathrm{C}$ ), the percentage of palmitic acid of Chemlali oil is slightly over $20 \%$ while the percentage of oleic acid is less than 55\%. In fact, high temperatures delay the fatty acid biosynthesis. For the Chemlali Sfax variety, the high amount of palmitic acid can be problematic for monocultivar producers wishing to harvest early to get green fruity aroma olive oil.

For all the Zarrazi oil samples and sixteen of the Chetoui sam-

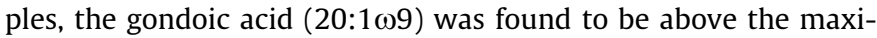
mum value fixed by the International Olive Oil Council (IOOC, 2008). Therefore, it appears that the values fixed by the IOOC can be too low and should be revised to take into account the specificity of Tunisian varieties. This statement was also developed by Pinatel, Ollivier and Artaud (2006) when they focused on the fatty acid compositions of olive oils produced in the world. The same authors have enumerated 24 French varieties where the amounts of some fatty acids could be outside the range of changes in fatty acid percentages set by the International Olive Oil Council and the European Regulation (Pinatel, Ollivier, \& Artaud, 2006). MUI values are strongly correlated with oleic acid, major fatty acid of VOOs. The highest mean indexes were observed for Zarrazi (5.43) and Oueslati (5.39) varieties followed by Chetoui's one (4.99). Zarrazi oil is characterised with high level of oleic acid (70.67-73.59\%), moderate linoleic acid (10.40-12.72\%) and a small percentage of palmitic acid (8.95-9.37\%). Chemchali mean MUI showed an intermediate value (3.94) while the lowest mean indexes were observed for Chemlali Sfax (3.13) and Zalmati (3.05) varieties.

TUI values take into account mainly oleic and linoleic acids which explains the similar variation to the MUI. Zarrazi, Oueslati and Chetoui VOOs present higher rates in unsaturated fatty acids than Chemchali, Chemlali Sfax and Zalmati oils.

The PUI reflects the richness of oils in linoleic and linolenic acids. The highest mean value of PUI is obtained for Chetoui variety VOO. In fact, linoleic acid level varies from $10.14 \%$ to $20.04 \%$ with stage of maturity and origin. Linoleic acid increases gradually with maturity (Baccouri et al., 2007). This variation is due to the fact that, with the formation of oleic acid, the enzyme oleate desaturase is active to transform oleic acid into linoleic acid (Gutierrez, Jimenez, Ruiz, \& Albi, 1999).

Finally, OPI evaluates the level of the odd fatty acids of the six Tunisian olive oil varieties. Chemlali Sfax and Zalmati oils have the highest mean OPI values (1.14) followed by Chemchali (1.05), Chetoui (1.02) and Oueslati (0.97). Zarrazi oil has the lowest OPI value $(0.80)$.

Squalene can constitute up to $90 \%$ of the hydrocarbon fraction of olive oil. It is a natural antioxidant in the non-saponifiable fraction of VOO, and exogenously administered in the diet, it reinforces the endogenous antioxidant system against oxidative damage (Mateos, Dominguez, Espartero, \& Cert, 2003). Squalene level varies with variety, but also with origin. According to Samaniego-Sanchez, 
Table 1

Physico-chemical characteristics and fatty acids (\%) of six Tunisian olive oil varieties.

\begin{tabular}{|c|c|c|c|c|c|c|c|c|c|c|c|c|c|c|c|c|c|c|c|}
\hline \multirow[t]{2}{*}{$\begin{array}{l}\text { Varieties } \\
n \\
\text { Studied localities }\end{array}$} & \multicolumn{3}{|c|}{$\begin{array}{l}\text { Chemchali } \\
5 \\
1 \\
\end{array}$} & \multicolumn{3}{|c|}{$\begin{array}{l}\text { Chemlali Sfax } \\
63 \\
14 \\
\end{array}$} & \multicolumn{3}{|c|}{$\begin{array}{l}\text { Chetoui } \\
41 \\
9 \\
\end{array}$} & \multicolumn{3}{|c|}{$\begin{array}{l}\text { Oueslati } \\
14 \\
3 \\
\end{array}$} & \multicolumn{3}{|c|}{$\begin{array}{l}\text { Zalmati } \\
5 \\
1 \\
\end{array}$} & \multicolumn{3}{|l|}{$\begin{array}{l}\text { Zarrazi } \\
5 \\
1 \\
\end{array}$} & \multirow[t]{2}{*}{$\begin{array}{l}\mathrm{IOOC}^{\mathrm{a}} \\
2011\end{array}$} \\
\hline & Mean & Min & Max & Mean & Min & Max & Mean & Min & $\operatorname{Max}$ & Mean & Min & Max & Mean & Min & Max & Mean & Min & Max & \\
\hline $\mathrm{MI}^{\mathrm{b}}$ & 3.71 & 1.92 & 6.25 & 3.20 & 1.00 & 5.38 & 1.96 & 0.52 & 4.16 & 2.50 & 1.82 & 3.72 & 2.56 & 2.33 & 3.00 & 3.38 & 2.90 & 4.00 & \\
\hline $\mathrm{A}^{\mathrm{c}}$ (oleic acid, $\mathrm{g} / 100 \mathrm{~g}$ ) & 0.24 & 0.18 & 0.40 & 0.21 & 0.12 & 0.35 & 0.30 & 0.11 & 1.30 & 0.37 & 0.18 & 0.55 & 0.25 & 0.21 & 0.28 & 0.16 & 0.13 & 0.18 & $\leqslant 0.8$ \\
\hline $\mathrm{K}_{232}^{\mathrm{d}}$ & 1.80 & 1.32 & 2.34 & 1.81 & 1.10 & 2.46 & 1.83 & 1.06 & 2.34 & 1.71 & 1.54 & 1.97 & 1.86 & 1.22 & 2.22 & 1.54 & 1.41 & 1.79 & 2.5 \\
\hline$K_{270}{ }^{d}$ & 0.16 & 0.14 & 0.19 & 0.13 & 0.09 & 0.21 & 0.11 & 0.04 & 0.20 & 0.14 & 0.11 & 0.17 & 0.14 & 0.11 & 0.17 & 0.13 & 0.11 & 0.15 & 0.22 \\
\hline $\mathrm{PV}^{\mathrm{e}}\left(\right.$ meq $\left.\mathrm{O}_{2} / \mathrm{kg}\right)$ & 1.97 & 1.09 & 3.17 & 5.30 & 0.06 & 9.10 & 3.55 & 1.30 & 5.88 & 5.95 & 3.35 & 10.24 & 4.03 & 2.93 & 5.12 & 3.16 & 1.29 & 4.95 & $\leqslant 20$ \\
\hline Carotenes $(\mathrm{mg} / \mathrm{kg})$ & 3.51 & 2.51 & 6.10 & 5.49 & 2.31 & 8.89 & 8.88 & 3.93 & 17.19 & 6.55 & 3.96 & 8.98 & 3.28 & 1.92 & 4.03 & 5.36 & 4.07 & 6.65 & \\
\hline Chlorophylls (mg/kg) & 1.66 & 1.08 & 2.06 & 2.60 & 0.65 & 5.66 & 4.84 & 0.70 & 11.69 & 5.97 & 4.23 & 8.16 & 1.23 & 0.94 & 1.50 & 1.61 & 1.11 & 3.02 & \\
\hline $16: 0$ & 14.09 & 13.42 & 14.60 & 17.22 & 15.65 & 20.97 & 10.46 & 9.06 & 12.49 & 10.85 & 10.06 & 12.04 & 17.05 & 12.65 & 18.35 & 9.19 & 8.95 & 9.37 & $7.5-20$ \\
\hline $16: 1 \omega 9$ & 0.05 & 0.05 & 0.06 & 0.06 & 0.05 & 0.08 & 0.14 & 0.11 & 0.17 & 0.09 & 0.07 & 0.10 & 0.07 & 0.05 & 0.10 & 0.11 & 0.10 & 0.11 & \\
\hline $16: 1 \omega 7$ & 1.08 & 0.89 & 1.27 & 2.09 & 1.65 & 2.97 & 0.26 & 0.19 & 0.42 & 0.54 & 0.43 & 0.66 & 1.75 & 0.95 & 2.07 & 0.21 & 0.20 & 0.22 & \\
\hline $16: 1 \omega 9+16: 1 \omega 7$ & 1.13 & 0.94 & 1.33 & 2.15 & 1.70 & 3.05 & 0.40 & 0.30 & 0.59 & 0.63 & 0.50 & 0.76 & 1.82 & 1.00 & 2.17 & 0.32 & 0.30 & 0.33 & $0.3-3.5$ \\
\hline $17: 0$ & 0.04 & 0.04 & 0.04 & 0.04 & 0.03 & 0.05 & 0.05 & 0.04 & 0.07 & 0.04 & 0.04 & 0.04 & 0.05 & 0.04 & 0.05 & 0.04 & 0.04 & 0.04 & $\leqslant 0.3$ \\
\hline $17: 1 \omega 8$ & 0.06 & 0.05 & 0.07 & 0.07 & 0.06 & 0.09 & 0.05 & 0.04 & 0.08 & 0.06 & 0.05 & 0.06 & 0.07 & 0.06 & 0.07 & 0.04 & 0.04 & 0.04 & $\leqslant 0.3$ \\
\hline 18:0 & 2.76 & 2.65 & 2.83 & 2.46 & 2.12 & 2.83 & 2.88 & 2.34 & 3.43 & 2.33 & 2.01 & 2.60 & 2.64 & 2.47 & 3.03 & 3.63 & 3.38 & 3.82 & $0.5-5$ \\
\hline $18: 1 \omega 9$ & 65.30 & 63.08 & 68.61 & 58.14 & 49.66 & 63.64 & 68.17 & 61.76 & 73.47 & 72.07 & 69.83 & 74.22 & 57.48 & 53.76 & 65.54 & 71.75 & 70.67 & 73.59 & \\
\hline $18: 1 \omega 7$ & 2.48 & 2.21 & 2.74 & 3.06 & 2.67 & 3.58 & 1.19 & 0.93 & 1.50 & 1.67 & 1.47 & 1.90 & 2.77 & 1.92 & 3.03 & 1.03 & 0.97 & 1.06 & \\
\hline $18: 1 \omega 9+18: 1 \omega 7$ & 67.78 & 65.29 & 71.35 & 61.20 & 52.33 & 67.22 & 69.36 & 62.69 & 74.97 & 73.74 & 71.30 & 76.12 & 60.25 & 55.68 & 68.57 & 72.78 & 71.64 & 74.65 & $55-83$ \\
\hline $18: 2 \omega 6$ & 12.02 & 9.72 & 13.57 & 15.10 & 10.65 & 19.03 & 14.59 & 10.14 & 20.04 & 10.20 & 8.71 & 12.31 & 16.18 & 13.61 & 18.41 & 11.77 & 10.40 & 12.72 & $3.5-21$ \\
\hline $18: 3 \omega 3$ & 0.48 & 0.45 & 0.52 & 0.64 & 0.53 & 0.87 & 0.68 & 0.54 & 0.90 & 0.59 & 0.50 & 0.65 & 0.74 & 0.67 & 0.80 & 0.60 & 0.58 & 0.65 & $\leqslant 1$ \\
\hline $20: 0$ & 0.48 & 0.44 & 0.50 & 0.44 & 0.39 & 0.51 & 0.49 & 0.44 & 0.54 & 0.44 & 0.39 & 0.50 & 0.49 & 0.48 & 0.50 & 0.51 & 0.50 & 0.52 & $\leqslant 0.6$ \\
\hline $20: 1 \omega 9$ & 0.28 & 0.28 & 0.29 & 0.20 & 0.17 & 0.27 & 0.39 & 0.33 & 0.47 & 0.37 & 0.36 & 0.39 & 0.24 & 0.21 & 0.37 & 0.47 & 0.47 & 0.48 & $\leqslant 0.4$ \\
\hline $22: 0$ & 0.14 & 0.13 & 0.15 & 0.12 & 0.10 & 0.15 & 0.13 & 0.11 & 0.16 & 0.14 & 0.13 & 0.15 & 0.14 & 0.13 & 0.14 & 0.12 & 0.11 & 0.13 & $\leqslant 0.2$ \\
\hline $24: 0$ & 0.07 & 0.04 & 0.08 & 0.07 & 0.06 & 0.09 & 0.05 & 0.03 & 0.07 & 0.07 & 0.07 & 0.09 & 0.08 & 0.07 & 0.08 & 0.06 & 0.06 & 0.07 & $\leqslant 0.2$ \\
\hline Squalene $\mathrm{e}^{\mathrm{f}}$ & 0.68 & 0.64 & 0.72 & 0.28 & 0.13 & 0.47 & 0.46 & 0.37 & 0.53 & 0.52 & 0.39 & 0.63 & 0.28 & 0.24 & 0.36 & 0.46 & 0.44 & 0.47 & \\
\hline $\mathrm{MUI}^{\mathrm{g}}$ & 3.94 & 3.98 & 4.01 & 3.13 & 2.96 & 2.87 & 4.99 & 5.27 & 4.54 & 5.39 & 5.69 & 5.02 & 3.05 & 3.60 & 3.21 & 5.43 & 5.56 & 5.41 & \\
\hline $\mathrm{PUI}^{\mathrm{h}}$ & 0.71 & 0.61 & 0.77 & 0.77 & 0.61 & 0.81 & 1.09 & 0.89 & 1.25 & 0.78 & 0.73 & 0.84 & 0.83 & 0.90 & 0.87 & 0.91 & 0.84 & 0.96 & \\
\hline TUI $^{\mathrm{i}}$ & 4.65 & 4.59 & 4.79 & 3.90 & 3.57 & 3.68 & 6.08 & 6.16 & 5.79 & 6.17 & 6.41 & 5.86 & 3.88 & 4.50 & 4.08 & 6.34 & 6.40 & 6.37 & \\
\hline $\mathrm{OPI}^{\mathrm{j}}$ & 1.05 & 0.96 & 1.05 & 1.14 & 1.08 & 1.21 & 1.02 & 0.93 & 1.32 & 0.97 & 0.96 & 0.95 & 1.14 & 1.15 & 1.07 & 0.80 & 0.83 & 0.78 & \\
\hline
\end{tabular}

Crops: 2011/2012.

${ }^{\text {a }}$ International Olive Oil Council.

${ }^{b}$ Maturity index

c Acidity.

d Specific extinction coefficient at 232 and $270 \mathrm{~nm}$.

e Peroxyde value.

Values were determined as the \% of the total area of fatty acids and squalene.

g Mono-unsaturation index.

h Poly-unsaturation index

Total unsaturation index

j Odd parity index. 
Quesada-Granados, Lopez-Garcia de la Serrana, and LopezMartinez (2010), this parameter varies also with the extraction system.

The analytical procedure used for the determination of squalene allows for a quick comparison of squalene amounts in the varieties studied. The highest mean levels of squalene were observed with Chemchali $(0.68 \%)$ and Oueslati $(0.52 \%)$ oils. Chetoui and Zarrazi oils have a comparable mean level of squalene (0.46\%) Chemlali Sfax and Zalmati oils showed the lowest mean level of squalene ( $0.28 \%)$.

\subsection{Fatty acid "morphotypes"}

It is difficult from Table 1 to assess the similarities and differences between different oil varieties. A graphical representation of fatty acid compositions provides a rapid visual identification of olive oil characteristics. A radial plot allows creating "morphogram" with fatty acids of each. The "morphogram" allows the establishment of a characteristic "morphotypes" for each oil variety (Fig. 1). Chemlali Sfax and Zalmati showed very similar "morphotypes". This result was expected knowing that these two varieties, growing in the south of Tunisia, have very similar fatty acid compositions (Table 1). Chemlali Sfax and Zalmati are similar at the morphological and agronomic points. But, they have also similar olive oil compositions. Rekik Hakim, Grati-Kamoun, Makhloufi, and Rebai (2010) found a similarity of 92\% using the Simple Sequences Repeats (SSR) on the leaves. Ben-Ayed, GratiKamoun, Sans-Grout, Moreau, and Rebai (2012) using SSR on DNA extracted oils, found less similarity between these two varieties.

Chetoui and Zarrazi "morphotypes" have similar shapes. This resemblance reflects a similar fatty acid composition. Each of Chemchali and Oueslati oils has a specific "morphotype".

This radial representation of fatty acids is a true "fingerprint" for each variety. In many cases, the varietal origin of an oil can be quickly and visually identified by comparing its "morphogram" with different "morphotypes" of the database (Ollivier et al., 2007).

Fatty acid of 22 oil samples from Algeria and 5 from Morocco were determined. Table 2 gives the mean, minimum and maximum for fatty acid composition of each variety. Fatty acid compositions of Tunisian commercial VOOs $(n=51)$ and French PDO VOO samples $(n=36)$ were also established.

All the fatty acid compositions obtained were analysed by chemometric treatment. In order to verify quickly the information indicated by the producer about the varietal origin of commercial
Tunisian samples, the "morphogram" of each sample was visually compared by superpositioning it on the "morphotype" of the corresponding variety, through the Excel ${ }^{\circledR}$ application. Results were satisfying; for all samples, the varietal origin corresponded to the statements of the producers. Varietal origin will be confirmed again through the chemometric treatment.

\subsection{Fatty acid $P C A$}

Variability in fatty acid levels between oil samples led to perform multivariate statistical methods to describe the characteristics of oils coming from the different varieties and to assess their differences. Several approaches were previously used as univariate and multivariate analyses of variance or hierarchical and nonhierarchical classification methods (Bucci, Magrì, Magrì, Marini, \& Marini, 2002). Neuronal classification (Bucci et al., 2002) and stepwise linear discriminant analysis were also used (Ollivier et al., 2003). Compared to other physico-chemical parameters commonly measured (acidity, peroxide value, phenols, tocopherols, etc.), fatty acids are the most stable and the most indicative for characterising a given VOO (Ollivier et al., 2003).

The characteristics of Tunisian olive oils was evaluated through a fatty acid and squalene PCA (Fig. 2) of Algerian (Azeradj, Blanquette, Bouricha, Chemlal, Limli and Sigoise varieties), Moroccan (Moroccan Picholine variety) and Tunisian VOOs (samples made in the laboratory and commercial ones). The score plot (Fig. 2A) obtained with the first and third components ( $\mathrm{PC} 1=45 \%$ and PC $3=13 \%$ of explained variance) showed that Tunisian olive oils can be easily distinguished from Moroccan ones.

Algerian olive oils were represented by six varieties which explain the dispersion of the corresponding point on the PCA. Some Algerian oil samples (Blanquette, $n=7$ ) overlap into the Chetoui group (Fig. 2A). This result confirms the hypothesis of Loussert and Brousse (1978) that the Chetoui and the Blanquette correspond to one common variety. In fact, Blanquette variety is collected from the north eastern of Algeria near the Chetoui's growing area in Tunisia. There is on the first and the third principal components an overlay between Chemlali and some Algerian varieties. A better separation between those two classes can be observed on the first and the fifth principal components ( $\mathrm{PC} 1=45 \%$; $\mathrm{PC} 5=7 \%$ ). But, there is also a small overlay between Chemchali and some other Algerian samples. Except the Blanquette variety, it was clear that there was information related to the geographic origin of Tunisian and Algerian VOOs.
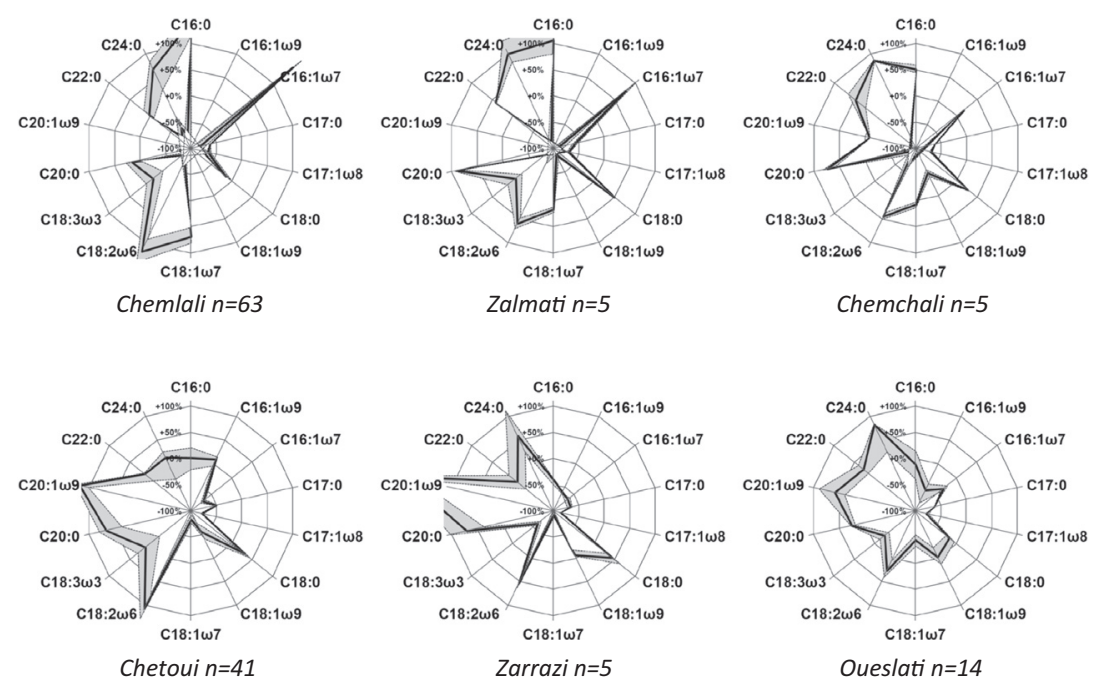

Fig. 1. "Morphotypes" from fatty acids of six Tunisian olive oil varieties. 
Table 2

Fatty acid compositions (\%) of 27 Maghrebian virgin olive oil samples.

\begin{tabular}{|c|c|c|c|c|c|c|c|c|c|c|c|c|c|c|c|c|c|c|c|}
\hline \multirow[t]{2}{*}{$\begin{array}{l}\text { VOOs } \\
n\end{array}$} & \multicolumn{2}{|c|}{$\begin{array}{l}\text { Azeradj } \\
4\end{array}$} & \multirow[b]{2}{*}{ Max } & \multicolumn{2}{|c|}{$\begin{array}{l}\text { Blanquette } \\
7\end{array}$} & \multirow[b]{2}{*}{ Max } & \multicolumn{2}{|c|}{$\begin{array}{l}\text { Bouricha } \\
2\end{array}$} & \multirow[b]{2}{*}{ Max } & \multicolumn{2}{|c|}{$\begin{array}{l}\text { Chemlal } \\
5\end{array}$} & \multirow[b]{2}{*}{ Max } & \multicolumn{2}{|l|}{$\begin{array}{l}\text { Limli } \\
3\end{array}$} & \multirow[b]{2}{*}{ Max } & \multirow{2}{*}{$\begin{array}{l}\text { Sigoise } \\
1 \\
\text { Mean }\end{array}$} & \multicolumn{2}{|c|}{$\begin{array}{l}\text { Morrocan Picholine } \\
5\end{array}$} & \multirow[b]{2}{*}{ Max } \\
\hline & Mean & Min & & Mean & Min & & Mean & Min & & Mean & Min & & Mean & Min & & & Mean & Min & \\
\hline 16:0 & 13.93 & 13.06 & 14.48 & 10.72 & 9.50 & 11.60 & 10.55 & 9.50 & 11.60 & 10.55 & 9.50 & 1.60 & 15.42 & 15.10 & 15.80 & 13.08 & 8.72 & 7.96 & 9.81 \\
\hline $16: 1 \omega 9$ & 0.04 & 0.02 & 0.08 & 0.14 & 0.13 & 0.16 & 0.14 & 0.13 & 0.16 & 0.14 & 0.13 & 0.16 & 0.04 & 0.04 & 0.05 & 0.17 & 0.19 & 0.16 & 0.23 \\
\hline $16: 1 \omega 7$ & 1.25 & 1.09 & 1.43 & 0.33 & 0.23 & 0.39 & 0.31 & 0.23 & 0.39 & 0.31 & 0.23 & 0.39 & 1.59 & 1.39 & 1.92 & 1.47 & 0.47 & 0.41 & 0.56 \\
\hline 17:0 & 0.16 & 0.10 & 0.20 & 0.05 & 0.04 & 0.05 & 0.05 & 0.04 & 0.05 & 0.05 & 0.04 & 0.05 & 0.04 & 0.04 & 0.04 & 0.05 & 0.04 & 0.04 & 0.04 \\
\hline $17: 1 \omega 8$ & 0.27 & 0.17 & 0.32 & 0.06 & 0.05 & 0.06 & 0.06 & 0.05 & 0.06 & 0.06 & 0.05 & 0.06 & 0.06 & 0.06 & 0.07 & 0.09 & 0.06 & 0.05 & 0.06 \\
\hline 18:0 & 2.72 & 2.53 & 2.93 & 2.70 & 2.57 & 2.93 & 2.75 & 2.57 & 2.93 & 2.75 & 2.57 & 2.93 & 3.72 & 3.45 & 3.96 & 2.42 & 2.61 & 2.34 & 3.07 \\
\hline $18: 1 \omega 9$ & 72.30 & 71.03 & 74.18 & 66.86 & 64.53 & 68.56 & 66.54 & 64.53 & 68.56 & 66.54 & 64.53 & 68.56 & 68.96 & 68.54 & 69.55 & 66.16 & 72.59 & 69.53 & 77.74 \\
\hline $18: 1 \omega 7$ & 2.41 & 2.26 & 2.57 & 1.37 & 1.14 & 1.50 & 1.32 & 1.14 & 1.50 & 1.32 & 1.14 & 1.50 & 2.34 & 2.13 & 2.73 & 2.74 & 1.55 & 1.35 & 1.89 \\
\hline $18: 2 \omega 6$ & 4.93 & 4.41 & 5.42 & 15.58 & 13.90 & 16.76 & 15.33 & 13.90 & 16.76 & 15.33 & 13.90 & 16.76 & 6.28 & 6.25 & 6.30 & 11.62 & 11.79 & 7.83 & 14.72 \\
\hline $18: 3 \omega 3$ & 0.62 & 0.60 & 0.67 & 0.69 & 0.61 & 0.78 & 0.70 & 0.61 & 0.78 & 0.70 & 0.61 & 0.78 & 0.47 & 0.41 & 0.55 & 1.01 & 0.94 & 0.78 & 1.11 \\
\hline $20: 0$ & 0.40 & 0.40 & 0.42 & 0.45 & 0.43 & 0.49 & 0.46 & 0.43 & 0.49 & 0.46 & 0.43 & 0.49 & 0.42 & 0.41 & 0.44 & 0.39 & 0.29 & 0.25 & 0.33 \\
\hline $20: 1 \omega 9$ & 0.21 & 0.20 & 0.25 & 0.39 & 0.35 & 0.42 & 0.39 & 0.35 & 0.42 & 0.39 & 0.35 & 0.42 & 0.17 & 0.16 & 0.18 & 0.31 & 0.35 & 0.31 & 0.37 \\
\hline 22:0 & 0.12 & 0.11 & 0.13 & 0.14 & 0.12 & 0.15 & 0.13 & 0.12 & 0.15 & 0.13 & 0.12 & 0.15 & 0.10 & 0.10 & 0.10 & 0.13 & 0.06 & 0.05 & 0.07 \\
\hline $24: 0$ & 0.07 & 0.07 & 0.08 & 0.06 & 0.06 & 0.07 & 0.06 & 0.06 & 0.07 & 0.06 & 0.06 & 0.07 & 0.06 & 0.05 & 0.08 & 0.07 & 0.03 & 0.03 & 0.04 \\
\hline Squalene ${ }^{a}$ & 0.55 & 0.47 & 0.76 & 0.48 & 0.42 & 0.52 & 0.47 & 0.42 & 0.52 & 0.47 & 0.42 & 0.52 & 0.34 & 0.26 & 0.47 & 0.32 & 0.31 & 0.25 & 0.38 \\
\hline MUI $^{\mathrm{b}}$ & 4.39 & 4.60 & 4.32 & 4.90 & 5.23 & 4.65 & 4.91 & 5.23 & 4.65 & 4.91 & 5.23 & 4.65 & 3.70 & 3.78 & 3.65 & 4.40 & 6.40 & 6.73 & 6.05 \\
\hline $\mathrm{PUI}^{\mathrm{c}}$ & 0.32 & 0.31 & 0.33 & 1.15 & 1.14 & 1.15 & 1.14 & 1.14 & 1.15 & 1.14 & 1.14 & 1.15 & 0.34 & 0.35 & 0.34 & 0.78 & 1.08 & 0.81 & 1.18 \\
\hline TUI $^{\mathrm{d}}$ & 4.71 & 4.91 & 4.66 & 6.05 & 6.37 & 5.80 & 6.06 & 6.37 & 5.80 & 6.06 & 6.37 & 5.80 & 4.04 & 4.13 & 3.99 & 5.18 & 7.48 & 7.54 & 7.24 \\
\hline $\mathrm{OPI}^{\mathrm{e}}$ & 4.39 & 2.82 & 4.97 & 1.08 & 0.96 & 1.09 & 1.03 & 0.96 & 1.09 & 1.03 & 0.96 & 1.09 & 1.02 & 0.97 & 1.08 & 1.36 & 1.00 & 0.99 & 0.91 \\
\hline
\end{tabular}

Crops: 2010/2011 and 2011/2012.

Values were determined as the \% of the total area of fatty acids and squalene.

b Mono-unsaturation index.

c Poly-unsaturation index.

Total unsaturation index.

e Odd parity index. 
The score plot (Fig. 2A) showed also that Chemlali Sfax, major Tunisian variety, can be easily separated from Chetoui, Oueslati, Chemchali and Zarrazi varieties. Correlation loadings (Fig. 2B) explained that Chemlali and Zalmati are characterised with high

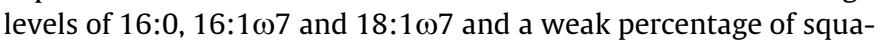
lene. However, Chetoui and Oueslati are distinguished with high

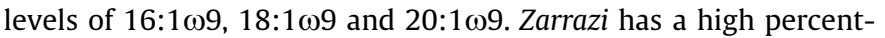

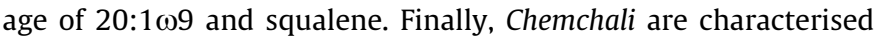
with high levels of 20:0 and 22:0 and squalene. These results show the importance of analysing the minor fatty acids to characterise the different varieties.

The commercial Tunisian VOOs were classified under their expected varietal group, which allows us to verify the authenticity of the information declared by the seller on the product's origin. Commercial Chemlali Sfax VOO samples coming from the crop year 2010-2011 form a subset in the set of Chemlali Sfax variety. This result can be explained with the effect of climatic characteristics of the year. In fact, the annual average rainfall was very low for the 2010-2011 harvest years in the centre and the south of the country and the olive tree productivity was very low.
A fatty acid and squalene PCA of Tunisian VOO samples produced in the laboratory, commercial ones $(n=184)$ and PDO French VOO samples $(n=36)$ was performed. Once again, the specificity of the Tunisian olive oil was confirmed through the obtained score plot (PC1 $=45 \%$ and $\mathrm{PC} 2=23 \%$ of explained variance). In fact, they can be easily separated from the foreign oils. French VOOs were assembled in the lower right quart of the score plot. Compared to the French PDO samples, the Tunisian VOO samples are

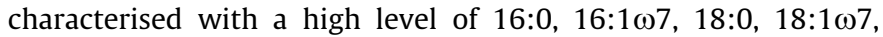

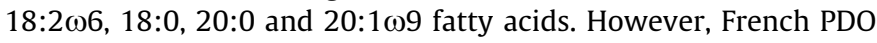

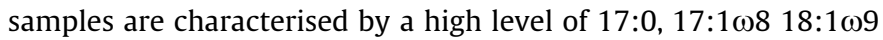
fatty acids and squalene.

\subsection{Near Infrared spectra}

Spectra obtained for all samples of virgin olive oils were similar to naked eye. Typical spectra of Tunisian virgin olive oil samples are presented on Fig. 3A. The band assessments were realised according to literature (Riaublanc, Bertrand, \& Dufour, 2000). The obtained spectral data were analysed by chemometric treatment.

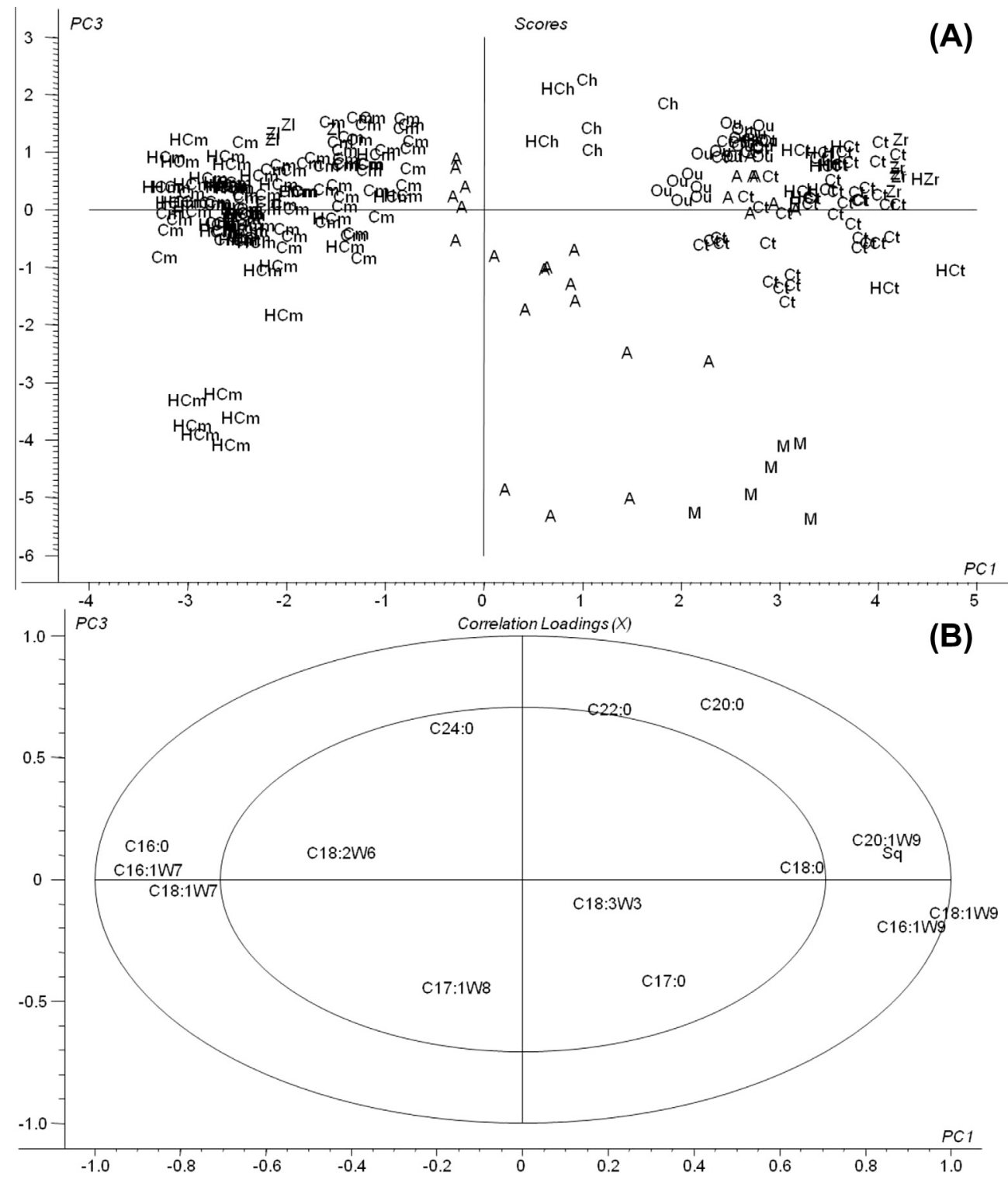

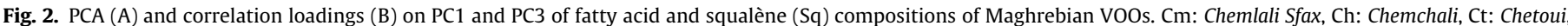

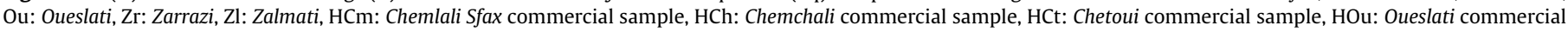
sample, HZR: Zarrazi commercial sample, A: Algerian samples, M: Moroccan sample. 


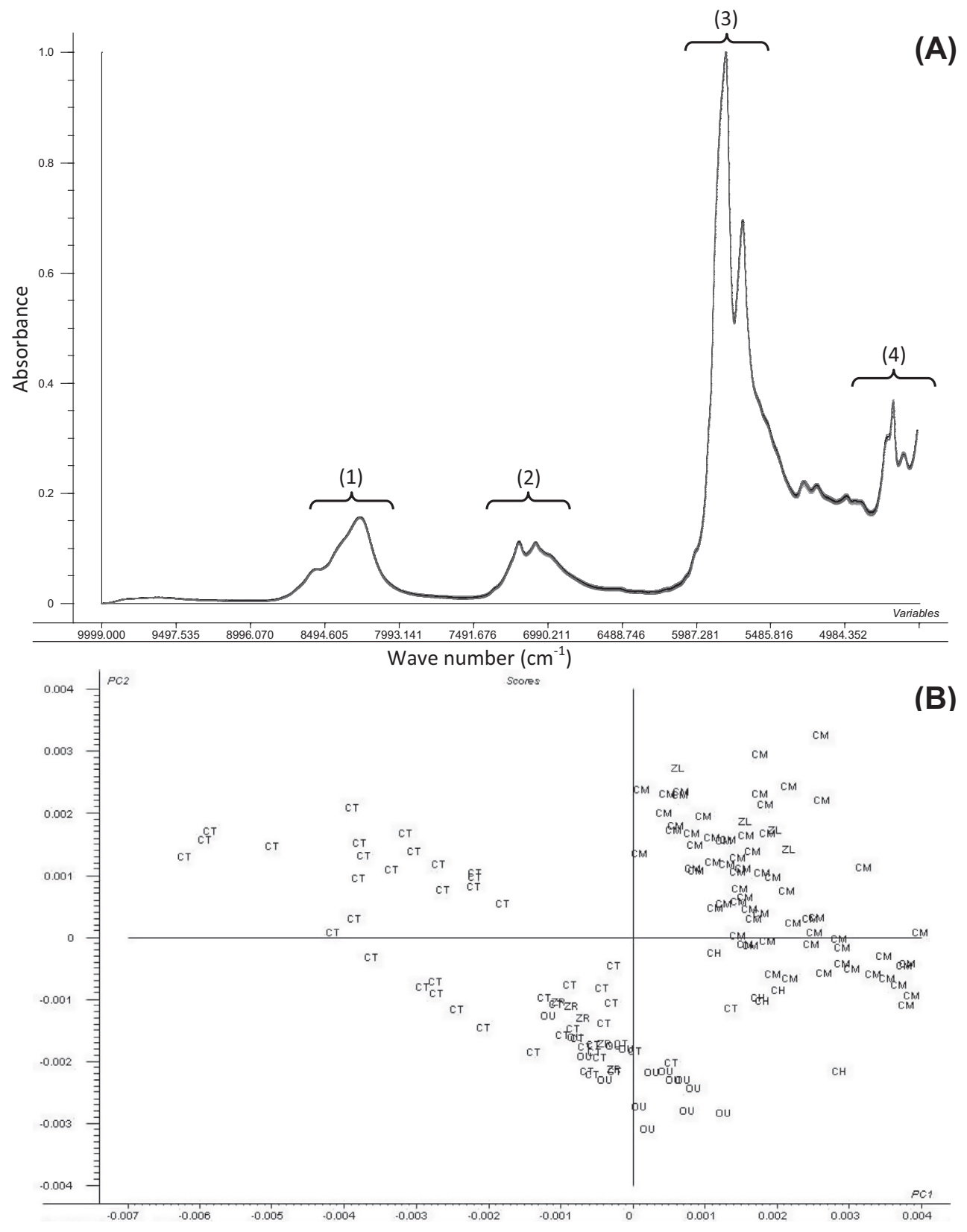

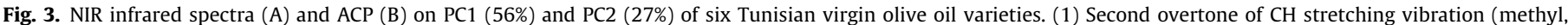

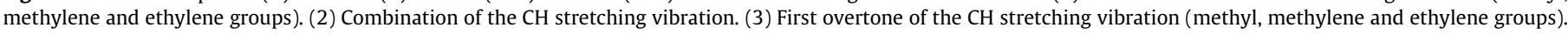
(4) Combination of the $\mathrm{CH}$ stretching vibration with other vibrational modes.

\subsection{Near Infrared ACP}

In order to examine the data structure, a principal component analysis (PCA) was performed on the 133 first derived spectra of Tunisian laboratory VOO samples (Fig. 3B). The score plot ( $\mathrm{PC} 1=56 \%$ and $\mathrm{PC} 2=27 \%$ of explained variance) showed that NIR spectra bring information related to the varietal origin of VOOs. The Chemlali Sfax and Chetoui oils are correctly separated. But, there is on the two first principal components an overlay between Zarrazi and Chetoui oils and between Zalmati and Chemlali Sfax oils.

\subsection{Classification in varietal origins by SIMCA}

SIMCA identification allows assigning new objects to the class to which they show the largest similarity. The results obtained for all the samples used in prediction set are presented in Table 3.
With NIR spectroscopy data, the models give respectively for Chemlali Sfax, Chetoui and Oueslati oils, 89.55\%, 92.53\% and 98.50\% of correct classifications (\%CC).

One sample of Chemlali Sfax was not recognised (false negative). Whereas, three commercial Chetoui samples were recognised as Chemlali Sfax (false positive). Zalmati and Chemchali samples ( $n=10)$ of the group "Other Voos" were recognised as a Chemlali Sfax (false positive). With Chetoui model, two samples of commercial Chemlali Sfax (harvest crop 2010-2012) were predicted as Chetoui (false positive). Five samples of Oueslati were recognised as Chetoui (false positive) and three samples of the group "Other VOOs" were classified as Chetoui. The best results were obtained with Oueslati model. Only two "Other VOOs" samples were recognised as Oueslati (false positive).

With NIR technique, all the foreign studied oils (Algerian, French and Moroccan), even the Blanquette samples, were not 
Table 3

Prediction of VOO varietal origins by SIMCA of NIR spectra and fatty acid compositions.

\begin{tabular}{|c|c|c|c|c|c|c|}
\hline \multirow[t]{2}{*}{ Real origin } & \multicolumn{3}{|c|}{ Predicted origin - NIR } & \multicolumn{3}{|c|}{ Predicted origin - Fatty acids } \\
\hline & Chemlali & Chetoui & Oueslati & Chemlali & Chetoui & Oueslati \\
\hline Chemlali Sfax $(n=33)$ & 32 & 2 & 0 & 29 & 0 & 0 \\
\hline Chetoui $(n=17)$ & 3 & 17 & 0 & 0 & 17 & 0 \\
\hline Oueslati $(n=5)$ & 0 & 5 & 5 & 0 & 0 & 4 \\
\hline Others VOOs $(n=79)$ & 10 & 3 & 2 & 2 & 7 & 0 \\
\hline$\% \mathrm{CC}$ & 89.55 & 92.53 & 98.50 & 95.52 & 94.77 & 99.25 \\
\hline
\end{tabular}

Training samples $n=111$; prediction samples $n=134$. \%CC: \% correct classification.

Others VOOs: Algerian $(n=22)$, French PDOs $(n=36)$, Moroccan $(n=5)$, Chemchali $(n=5)$, Zalmati $(n=5)$, Zarrazi $(n=6)$.

recognised by any of the three models. This result proves that there are soil and environment effects on the oil composition in general.

With fatty acid compositions, there are $95.52 \%$ of correct classification for Chemlali Sfax, 94.77\% for Chetoui and 99.25\% for Oueslati oils. Four Chemlali Sfax oils, coming from the crop year 2010-2011, were not recognised (false negative). It is likely that the error in the authentication of Chemlali Sfax samples (harvest 2010-2011) is due to particular weather conditions for this year of production. Two Zalmati samples from the "Other VOOs" group are predicted as Chemlali Sfax (false positive). This result can be expected knowing that these two varieties have a very similar fatty acid composition. The seven Blanquette, Algerian oil samples, were predicted as Chetoui. Once again, the result confirms the hypothesis on the identity between these two cultivars (Loussert and Brousse, 1978). One Oueslati sample was not recognised (false negative).

Finally, both NIR and fatty acid composition methods have the potential to determine the varietal origin of Tunisian VOOs.

\section{Conclusion}

An accurate data of fatty acid composition and NIR spectra associated to chemometric treatment allows us to characterise and authenticate six Tunisian olive oil varieties. These oils were distinguished from Maghrebian (Algerian and Moroccan) and French PDO VOOs. The graphical representation of the fatty acid and NIR spectra are rapid tools for the identification of monocultivar VOOs. They are also efficient tools in the authentication of commercial olive oils, and can be used to ensure the traceability of the product.

\section{Acknowledgements}

The authors are grateful to the Tunisian Ministry of Higher Education and Scientific Research and the French Ministry of Foreign Affairs for the project $11 \mathrm{G} 1214$, program (PHC-Utique) and also to the Committee for University Cooperation (CMCU). A lot of thanks to the technical staff of the Unit of research Technology and Quality at "Institut de l'Olivier", particularly to Mr. Neji Arous, Mr. Soufian ELghozzi and Ms. Mariem Hbaib, We also thank Mr. Christian Pinatel from the "Centre Technique de l'Olivier Aix-en-Provence (France)", Pr. Mohamed Barki from the University of Beni Mellal, Marocco and Ms. Nora Boudour-Benrachou from the "Institute of Agronomy, university Center of El Tärf, Algeria. We appreciate the efforts of the mentioned people to provide us with samples in order to achieve this work.

\section{References}

APIA. (2008). Etude sur le conditionnement de l'huile d'olive tunisienne. Rapport $361 \mathrm{p}$.

Baccouri, B., Zarrouk, W., Krichene, D., Nouairi, I., Ben Youssef, N., Daoud, D., et al. (2007). Influence of fruit ripening and crop yield on chemical properties of virgin olive oils from seven selected oleasters (Olea europeae L.). Journal of Agronomy, 6(3), 388-396.
Ben-Ayed, R., Grati-Kamoun, N., Sans-Grout, C., Moreau, F., \& Rebai, A. (2012). Characterization and authenticity of virgin olive oil (Olea europaea L.) cultivars by microsatellite markers. European Food Research and Technology, 234(2), 263-271.

Bevilacqua, M., Bucci, R., Magrì, A. D., Magrì, A. L., \& Marini, F. (2012). Tracing the origin of extra virgin olive oils by infrared spectroscopy and chemometrics: A case study. Analytica Chimica Acta, 717, 39-51.

Bucci, R., Magrì, A. D., Magrì, A. L., Marini, D., \& Marini, F. (2002). Chemical authentication of extra virgin olive oil varieties by supervised chemometric procedures. Journal of Agricultural and Food Chemistry, 50, 413-418.

European Standard NF EN ISO 5508. (1995). Analysis by gas chromatography of methyl esters of fatty acids. Paris, France: AFNOR.

European Standard NF EN ISO 5509 Norm. (2000). Preparation of methyl esters of fatty acids. Paris, France: AFNOR.

Galtier, O., Dupuy, N., Le Dréau, Y., Ollivier, D., Pinatel, C., Kister, J., et al. (2007). Geographic origins and compositions of virgin olive oils determinated by chemometric analysis of NIR spectra. Analytica Chimica Acta, 595, 136-144.

Galtier, O., Abbas, N., Le Dréau, Y., Rébufa, C., Kister, J., Artaud, J., et al. (2011). Comparison of PLS1-DA and SIMCA for classification by origin of crude petroleum by MIR and virgin olive oils by NIR for different spectral regions. Vibrational Spectroscopy, 55, 132-140.

Grati-Kamoun, N., \& Khlif, M. (2001). Caractérisation technologique des variétés d'olivier cultivées en Tunisie. Ezzaitouna, 2001, 69p [numéro spécial].

Grati-Kamoun, N., Lamy Mahmoud, F., Rebaï, A., Gargouri, A., Panaud, O., \& Saar, A (2006). Genetic diversity assessment of Tunisian olive tree (Olea europaea L.) cultivars using AFLP markers. Genetic Resources and Crop Evolution, 53, 265-275.

Grati-Kamoun, N., \& Zarrouk, W. (2012). Exploratory chemometric analysis for the characterization of Tunisian olive cultivars according to their lipid and sterolic profile. International Journal of Food Science and Technology, 47(7), 1496-1504.

Gutierrez, F., Jımenez, B., Ruız, A., \& Albi, M. A. (1999). Effect of olive ripeness on the oxidative stability of virgin olive oil extracted from the varieties Picual and Hojiblanca and on the different components involved. Journal of Agricultural and Food Chemistry, 47, 121-127.

IOOC (International Olive Oil Council). (2008). Trade standard applying to olive oils and olive-pomace oils. COI/T.15/NC n_3/Rev. 3, URL at: <http:// www.internationaloliveoil.org/downloads $>$.

Issaoui, M., Dabbou, S., Echbili, A., Rjiba, I., Gazzah, N., Trigui, A., et al. (2007). Biochemical characterisation of some Tunisian virgin olive oils obtained from different cultivars growing in Sfax National Collection. Journal of Food, Agriculture E' Environment, 5(1), 17-21.

Jolliffe, I. (2002). Principal component analysis (2nd ed.). Springer.

Loussert, R., \& Brousse, G. (1978). L'Olivier. p100. Paris, France: G.P. Maisonneuve \& Larose.

Mateos, R., Dominguez, M. M., Espartero, J. L., \& Cert, A. (2003). Antioxidant effect of phenolic compounds, alpha-tocopherol, and other minor components in virgin olive oil. Journal of Agricultural and Food Chemistry, 51, 7170-7175.

Minguez-Mosquera, M. I., Rejano-Navarro, L., Gandul-Rojas, B., Sanchez-Gomez, A. H., \& Garrido-Fernandez, J. (1991). Color pigment correlation in virgin olive oil. Journal of American Oil Chemists' Society, 68, 332-336.

Ollivier, D., Artaud, J., Pinatel, C., Durbec, J. P., \& Guérère, M. (2003). Triacylglycerol and fatty acid compositions of French virgin olive oils. Characterization by chemometrics. Journal of Agricultural and Food Chemistry, 51, 5723-5731.

Ollivier, D., Pinatel, C., Dupuy, N., Guérère, M., \& Artaud, J. (2007). Caractérisations sensorielles et chimiques d'huiles d'olive vierges de six AOC françaises. Oléagineux, Corps Gras, Lipides, 14(2), 116-129.

Ouni, Y., Flamini, G., Douja, D., \& Zarrouk, M. (2011). Effect of cultivar on minor components in Tunisia olive fruits cultivated in microclimate. Journal of Horticulture and Forestry, 3(1), 13-20.

Pinatel, C., Ollivier, D., \& Artaud, J. (2006). Qualité, sécurité alimentaire, traçabilité et typicité de nos productions. Le Nouvel Olivier, 52, 22-23.

Pinatel, C., Ollivier, D., Ollivier, V., \& Artaud, J. (2014). New approach to the determination of the origin of olive oils: morphograms and morphotypes (Part II). Olivae, 119(19), 48-62.

Rekik Hakim, I., Grati-Kamoun, N., Makhloufi, E., \& Rebai, A. (2010). Discovery and potential of SNP markers in characterization of Tunisian olive germplasm. Diversity, 2, 17-27.

Riaublanc, A., Bertrand, D., \& Dufour, E. (2000). Lipides in La spectroscopie infrarouge et ses applications analytiques. Paris: Tec et Doc, pp. 156-157. 
Samaniego-Sanchez, C., Quesada-Granados, J. J., Lopez-Garcia de la Serrana, H., \& Lopez-Martınez, M. C. (2010). $\beta$-Carotene, squalene and waxes determined by chromatographic method in picual extra virgin olive oil obtained by a new cold extraction system. Journal of Food Composition and Analysis, 23, 671-676.

Trigui, A., Msallem, M., \& Collaborateurs (2002). Catalogue des variétés autochtones et types locaux. Ministère de l'Agriculture, IRESA, Institut de l'Olivier. 159p.

Uceda, M., \& Frias, L. (1975) Harvest dates. Evolution of the fruit oil content, oil composition and oil quality. In Proc. Segundo. Seminario Oleicola Internacional, Cordoba, Spain, 6 Oct 1975, 125-130.
Wold, S., \& Sjöström, M. (1977). SIMCA: a method for analyzing chemical data in terms of similarity and analogy. In B. R. Kowalski (Ed.) (pp. 243-282) Washington, DC: American Chemical Society.

Wolff, J. P. (1968). Manuel d'analyse des corps gras. Paris: Azoulay. 370 p.

Woodcock, T. Downey, G. \& O'Donnell, C. P. (2008). Confirmation of declared provenance of European extra virgin olive oil samples by NIR spectroscopy. Journal of Agricultural and Food Chemistry, 56(23), 11520 11525. 